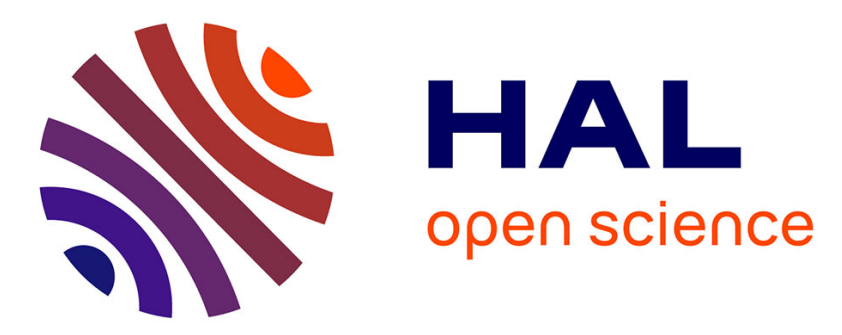

\title{
A Global Approach for the Design of a Rim- Driven Marine Turbine Generator for Sail Boat
}

Laurent Drouen, Jean-Frederic Charpentier, Eric Semail, Stéphane Clenet

\section{To cite this version:}

Laurent Drouen, Jean-Frederic Charpentier, Eric Semail, Stéphane Clenet. A Global Approach for the Design of a Rim- Driven Marine Turbine Generator for Sail Boat. XXth International Conference on Electrical Machines (ICEM 2012), Sep 2012, Marseille, France. pp.549 - 555, 10.1109/ICElMach.2012.6349923 . hal-01073606

\section{HAL Id: hal-01073606 https://hal.science/hal-01073606}

Submitted on 15 Sep 2017

HAL is a multi-disciplinary open access archive for the deposit and dissemination of scientific research documents, whether they are published or not. The documents may come from teaching and research institutions in France or abroad, or from public or private research centers.
L'archive ouverte pluridisciplinaire HAL, est destinée au dépôt et à la diffusion de documents scientifiques de niveau recherche, publiés ou non, émanant des établissements d'enseignement et de recherche français ou étrangers, des laboratoires publics ou privés. 


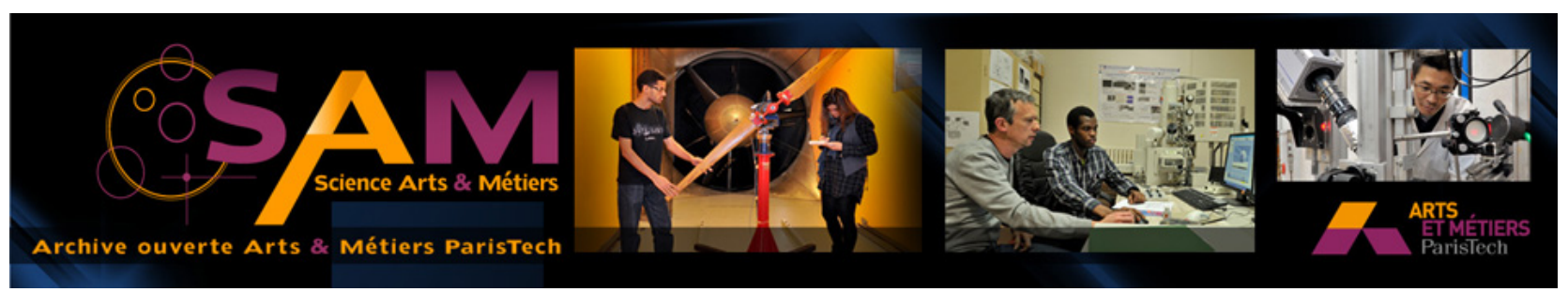

\section{Science Arts \& Métiers (SAM)}

is an open access repository that collects the work of Arts et Métiers ParisTech researchers and makes it freely available over the web where possible.

This is an author-deposited version published in: http://sam.ensam.eu

Handle ID: .http://hdl.handle.net/10985/8712

\section{To cite this version :}

Laurent DROUEN, Jean-Frederic CHARPENTIER, Eric SEMAIL, Stéphane CLENET, Eric SEMAIL - A Global Approach for the Design of a Rim- Driven Marine Turbine Generator for Sail Boat - In: XXth International Conference on Electrical Machines (ICEM), 2012, France, 2012-09 Electrical Machines (ICEM), 2012 XXth International Conference on - 2012 


\title{
A Global Approach for the Design of a Rim- Driven Marine Turbine Generator for Sail Boat.
}

\author{
L. Drouen, J.F. Charpentier, E. Semail, S. Clenet
}

\begin{abstract}
Development of new ways to provide clean onboard electric energy is a key feature for the sailing boat industry and sail race teams. This is why marine turbines (MT), are considered to provide onboard energy. These turbines can be used to harness kinetic energy of the water flow related to the ship motion. In this paper we propose to study an unconventional design of such a turbine where the electrical generator is located in the periphery of the blades and where the magnetic gap is water filled.

This kind of solution called "RIM DRIVEN" structure allows to increase the compactness and the robustness of the system. Due to the strong interaction of the multi physical phenomena, an electromagnetic model and a thermal model of the PM generator are associated with a hydrodynamic model of the blades and of the water flow in the underwater air gap. These models are used in a global coupled design approach in order to optimize, under constraints, the global efficiency of the system. This solution allows to optimize the system design.
\end{abstract}

Index Terms-Ship Power, Marine Turbines, PM Machine, Analytical models, multi physical approach.

\section{INTRODUCTION}

$\mathrm{P}$ ROVIDING clean onboard energy in a sailing ship is a key feature for the sail industry and the sailing race teams. The classical solutions to provide electrical energy in sailing boats are often based on the use of the secondary propulsion internal combustion engine associated with batteries and generator systems. However these systems are often noisy and generate pollution emission. This is why some secondary electrical propulsion systems are now proposed for sail ship [1]. Furthermore race regulation rules have recently strongly limited the use of fossil fuel in race ships. In a modern ship, equipments, such as systems of propulsion, security, navigation and comfort, are highly energy consuming. This is why some compact and powerful clean sources of energy are now needed in the sailing boats dedicated to boating and racing activities. One of the most interesting solutions to provide onboard clean energy, in terms of compactness and efficiency, is to put a marine turbine fixed to the ship hull. This turbine can harness the kinetic energy of the water flow created by the sail ship speed. The design challenges of such a system are to increase compactness, and robustness and also minimize the cost of the generator and turbine. The use of an unconventional solution based on the use of a Rim-Driven Turbine (RDT) is studied in this paper. In this solution a PM generator is fully integrated in the periphery of the turbine. This paper describes a global and multi-physical approach for the design of such a system. In this approach

This work was supported by the French Navy.

J.F. Charpentier is with the Research Institute of the French Naval Academy (IRENAV), Ecole Navale BCRM CC 600 - 29240 BREST Cedex 9, France (phone: (33) 298233924; email: jeanfrederic.charpentier@ecole-navale.fr)

E. Semail and S. Clenet are with the Laboratory of Electricity and Power Electronics (L2EP) of Lille, Arts et Métiers Paris Tech, 8, boulevard Louis XIV 59046 Lille Cedex (email: eric.semail@ensam.eu, stephane.clenet@ensam.eu)). the electromagnetic and thermal models of the generator are associated with two hydrodynamic models: one of the turbine and the other one for the water flow in the generator gap. The technical work presentation is divided in 3 parts: in section II the specificities of RDT systems are presented, in section III the models and their association are described and finally section IV shows and discusses the design results corresponding to a typical race boat specifications.

\section{RIM-DRIVEN TURBINE TECHNOLOGY}

In a rim driven system the active parts of an electrical radial flux PM machine are located in a duct which surrounds the blades of a horizontal-axis turbine or propeller as shown in Fig. 1. This kind of systems has been tested successfully for marine propulsion [2-4], and also for kinetic tidal energy systems [5,6]. It has been proved that this kind of solution allows to minimize the volume of the active part and to maximize the compactness and the robustness of the system as shown in [7] and [8]. It is also well known that using a ducted turbine leads to increase the hydrodynamic efficiency of the blades, and minimize vibration and cavitation phenomena and improve the protection of blades.

This is why this kind of system can be a very attractive solution to reach the design goals of a marine turbine dedicated to onboard energy generation in a sail ship.

To minimize the sealing problems (the classical systems need a rotating seal) and to improve the thermal behavior of the generator, the immersion of the gap in sea water can be envisaged. However, since most of the active elements are sensitive to sea water, they need to be covered, in this case, with a layer of specific coating (for example a specific polymer resin). This coating layer which appears in yellow in Fig. 1 increases significantly the value of the magnetic gap (distance between magnet and stator iron).

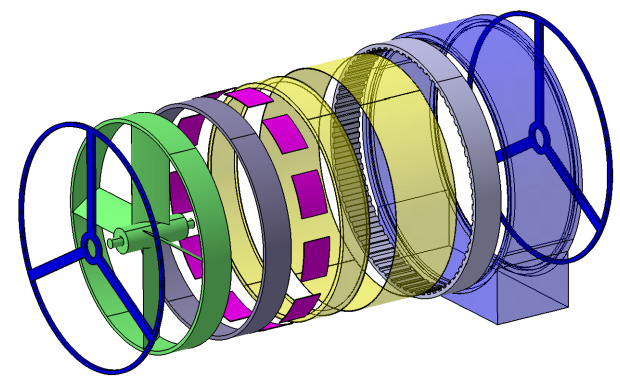

Fig 1. Principle of a rim-driven turbine

In this kind of system the main physical phenomena are related to electromagnetism, heat transfer (electromechanical and thermal behaviour of the generator) and also fluids mechanics (turbine blades performance and gap water flow behaviour). It must be noticed that other phenomena related to mechanical structure deformation 
linked to hydrodynamic drag and magnetic forces are not modelled in this work. However they may be a strong constraint in the system structure design and material choice. This is why some strong constraints on geometrical dimensions are introduced in the design process.

Fig. 2 shows the main phenomena which are considered and modelled in this study.

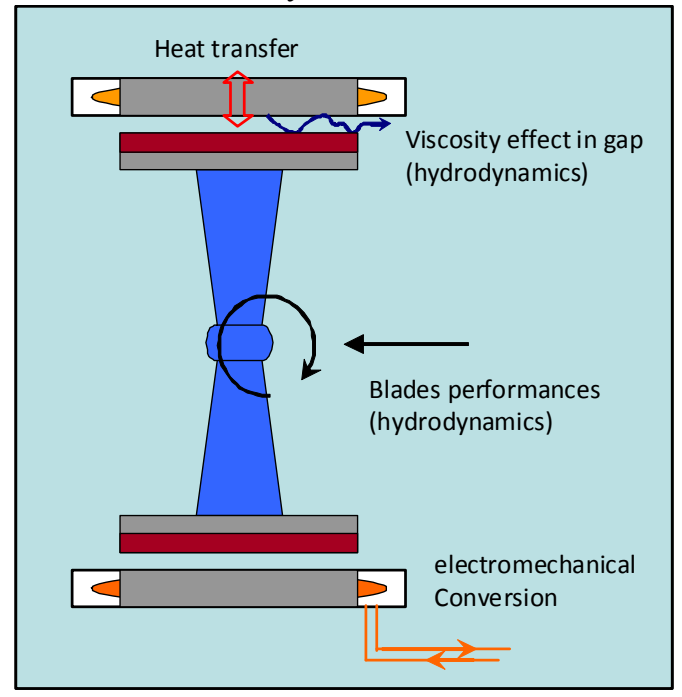

Fig 2. Multi physical phenomena in a RDT

The classical way to design a turbine/generator association is to design separately and sequentially the turbines blades and the generator parts. In this classical approach turbine blades are designed first and the "best" generator, for the rated point of the turbine, is determined in a second time.

It is obvious that the physical phenomena occurring in a RDT may have a contradictory influence on the global system behaviour if some main design parameters vary.

As a first example, for a given rotation speed, increasing the gap value makes it possible to minimize the viscosity losses in the immersed gap. However a high value of the gap is a highly penalising factor for the electromechanical performance of the PM generator. As a second example, the choice of the rated speed of the system must be a compromise between the hydrodynamics performance of the blades, the electromagnetic constraints on the machine design related to electrical frequency, iron losses and pole number and the heat transfer capability of the immersed gap. This is why it seems necessary to consider an approach where multi-physical models are coupled in a global approach of the RDT design. In this global approach turbine blades and the PM generator are designed simultaneously.

\section{DESIGN MODELS}

\section{A. Global description of the design method}

The models used in such a global approach are described in this section. These models are coupled as shown in Fig 3 which gives the global design optimization scheme. In this scheme the specifications are associated with the rated speed of the sail ship (speed of the ship used for the turbine calculation point)

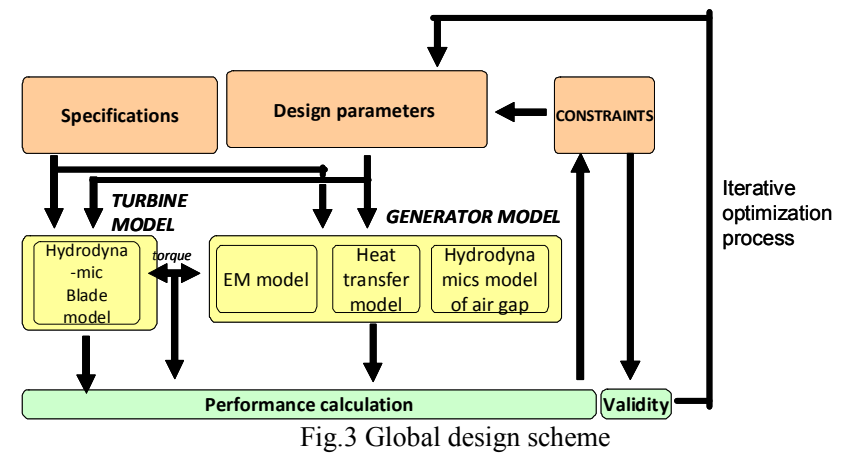

The design parameters are the geometrical parameters of the generator and the blades (twist law) as well as the rotating speed of the turbine. The constraints are related to geometrical constraints (mechanical, machining, etc.), to material constraints (induction level, demagnetization constrains, etc.), or to thermal constraints (maximal temperature). The used optimization method consists in a systematic estimation of the design parameters set in an iterative process to find the best compromise in terms of global efficiency (parametric analysis). This systematic method has been preferred to some more elaborated optimization methods because the used models are analytical and relatively simples. This simplicity allows using such a method in an iterative process with a reasonable calculation time (a few hours on a PC).

\section{B. Electromechanical Generator Model}

Fig. 4 describes the main geometrical parameters of the generator (for clarity reason the curvature of the machine, is not represented in the figure).

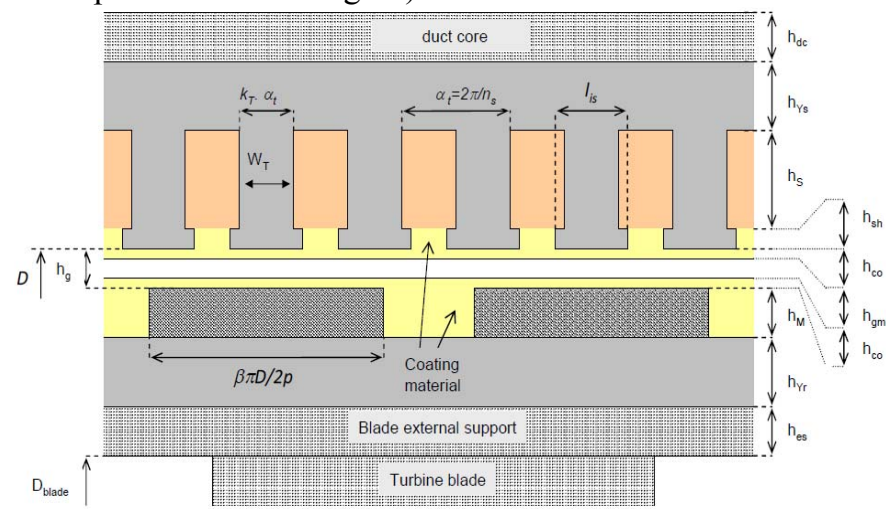

Fig. 4. Main dimensions of the electrical machine

In this figure $\alpha_{\mathrm{t}}, \mathrm{p} \mathrm{n}_{\mathrm{s}}, \mathrm{k}_{\mathrm{T}}, \beta$, are respectively the angular slot pitch, the number of slots, the number of pole pairs, the proportion of teeth and the magnet to pole width ratio . The parameters $h_{d c}, h_{Y s}, h_{Y r}, h_{S}, h_{S h}, h_{c o}, h_{g m}, h_{e s}, h_{m}$ (in meters) are respectively the duct core, stator and rotor yoke, slot, slot shoes, coating layer, mechanical gap, bade external rim, and magnet radial heights. The magnetic gap, $h_{g}$, comprises the mechanical gap and the coating layers (in stator and rotor sides). $\mathrm{D}(\mathrm{m})$ is the internal diameter of stator iron. $\mathrm{D}_{\text {blade }}(\mathrm{m})$ is the external diameter of the turbine blades.

The electrical machine is supposed to be connected to an $\mathrm{AC} / \mathrm{DC}$ converter. In this first order model we suppose that the currents in the electrical machine windings are sinusoidal, so the medium EM torque can be expressed as follow

$$
\mathrm{T}_{\mathrm{EM}}=\sqrt{2} \cdot \mathrm{k}_{\mathrm{w} 1} \cdot \mathrm{A}_{\mathrm{L}} \cdot \mathrm{B}_{1} \cdot\left(\pi \cdot \mathrm{D}^{2} \cdot \mathrm{L} / 4\right) \cdot \cos \psi
$$


where $k_{w 1}$ is the winding factor, $A_{L}(A / m)$ is the stator rms electric load, $B_{1}(T)$ is the peak value of the fundamental of the flux density created by the magnets at the stator surface, $\mathrm{L}(\mathrm{m})$ is the iron axial length and $\psi$ is the electrical angle between the stator current and the electromotive force induced by the rotor. The calculation of the flux density created by the magnets is derived from a 2D model [9] that solves the magnetic field equations in the gap by separating the polar and radial variables. This solution enables to express the flux density in a slotless PM machine as a Fourier series of spatial harmonics.

With the previous hypothesis, only the first spatial harmonic of this flux density is considered. The relationship between $B_{1}, h_{G}$, the magnets height $h_{M}$ and the number of pole pairs can then be expressed (eq.(2)).

$$
\begin{aligned}
& \mathrm{B}_{1}=\mathrm{k}_{\beta} \mathrm{B}_{\mathrm{r}} \frac{\mathrm{R}_{\mathrm{sm}}^{\mathrm{p}-1}\left(\mathrm{p}-1+2 \mathrm{R}_{\mathrm{rm}}^{\mathrm{p}+1}-(\mathrm{p}+1) \mathrm{R}_{\mathrm{rm}}^{2 \mathrm{p}}\right) \cdot 2 \mathrm{p} /\left(\mathrm{p}^{2}-1\right)}{\left(\mu_{\mathrm{r}}+1\right)\left(\mathrm{R}_{\mathrm{sm}}^{2 \mathrm{p}}-\mathrm{R}_{\mathrm{rm}}^{2 \mathrm{p}}\right)-\left(\mu_{\mathrm{r}}-1\right)\left(1-\mathrm{R}_{\mathrm{rm}}^{2 \mathrm{p}} \mathrm{R}_{\mathrm{sm}}^{2 \mathrm{p}}\right)} \\
& \mathrm{R}_{\mathrm{rm}}=1-\mathrm{h}_{\mathrm{M}} /\left(\mathrm{D} / 2-\mathrm{h}_{\mathrm{G}}\right) \\
& \mathrm{R}_{\mathrm{sm}}=1 /\left(1-2 \mathrm{~h}_{\mathrm{G}} / \mathrm{D}\right)
\end{aligned}
$$

Where $B_{r}$ is the magnetization value of the magnets, $\beta$ is the magnet to pole width ratio and $\mu_{r}$ is the magnets relative permeability. In addition, a coefficient $\mathrm{k}_{\mathrm{s}}$, which takes into account the slotting effect, is applied to the gap and magnet heights

$\mathrm{k}_{\mathrm{s}}=1+\mu_{\mathrm{o}} \cdot \mathrm{R}_{\mathrm{eq}} /\left(\mathrm{h}_{\mathrm{G}}+\mathrm{h}_{\mathrm{M}} / \mu_{\mathrm{r}}\right)$

Two formulas are used for the reluctance $R_{e q}$, depending on the gap thickness. These formulas can be found in [10]. The first one shall be used in the case of a thin gap and correspond to the well known Carter's coefficient. The second expression shall be used for thick air gaps.

Equation (1) allows to link the EM model to the hydrodynamic model of the immersed gap (calculation of the torque related to the viscosity, $\mathrm{T}_{\mathrm{v}}$ ) and the turbine blade hydrodynamics torque calculated by the hydrodynamics model of the blade, Q and the iron losses in the generator which are mainly caused by the rotation of the rotor.

$\mathrm{T}_{\mathrm{EM}}=\mathrm{Q}-\mathrm{P}_{\mathrm{Fe}} / \Omega-\mathrm{T}_{\mathrm{v}}$

Additional constraints are added to this model. The rotor and stator yoke minimum heights and the minimum proportion of teeth are chosen by using classical magnetic flux conservation considerations such as the flux density into the iron that must be lower than a maximum value $B_{\max }$ (that generally corresponds to the saturation limit of the magnetic material). These heights are determined by considering both superposed effects of magnets and windings on the flux density in iron. Another constraint concerns the magnet height minimal value. This minimal value is limited by demagnetization consideration taking into account the magnetic fields created by magnets and windings.

An additional constraints set concerns mechanical integrity: the tooth shape must follow the following criterion

$\mathrm{h}_{\mathrm{S}} / \mathrm{w}_{\mathrm{T}} \leq \mathrm{R}_{\max }$

$\mathrm{R}_{\max }$ is a ratio that represents a limit in terms of mechanical integrity of the teeth. Similarly, the magnets shape is chosen such that the ratio between magnet height and magnet width remains realistic

$\mathrm{h}_{\mathrm{M}} /(\beta \pi \mathrm{D} / 2 \mathrm{p}) \leq \mathrm{R}_{\max 2}$

Electromagnetic losses are calculated for each set of design parameters. These losses allow to estimate the generator efficiency and also to link the EM, the heat transfer and the hydrodynamic turbine performance models (as shown in (4)). The iron losses, are calculated thanks to classical estimations of specific losses $\mathrm{p}_{\mathrm{Fe}}(\mathrm{W} / \mathrm{kg})$ per unit mass in each part of the stator magnetic circuit.

$\mathrm{p}_{\mathrm{Fe}}=\mathrm{p}_{\mathrm{Fe}_{\mathrm{o}}} \cdot\left(\mathrm{f} / \mathrm{f}_{\mathrm{o}}\right)^{\mathrm{b}}\left(\mathrm{B}_{\mathrm{Fe}} / \mathrm{B}_{\mathrm{Feo}}\right)^{\mathrm{c}}$

where $f(H z)$ and $B_{F e}(T)$ are respectively the electrical frequency and flux density in the iron, $\mathrm{p}_{\mathrm{Feo}}(\mathrm{W} / \mathrm{kg})$ is the iron losses per unit mass at a given frequency $\mathrm{f}_{\mathrm{o}}$ and with a flux density $\mathrm{B}_{\mathrm{Feo}}$. Typical values corresponding to typical medium quality Fe-Si laminated steel datasheets are used $(\mathrm{b}=1.5$ and $\mathrm{c}=2.2)$. The Joule losses are estimated from the calculated value of the coils resistance $\left(R_{c}=R_{a}+R_{e w}\right)$. This value is calculated from the knowledge of the slot geometry, the slot fill factor and takes into account the contribution of both active part $\left(R_{a}\right)$ and endwindings $\left(R_{e w}\right)$.

$\mathrm{P}_{\mathrm{Cu}}=3 .\left(\mathrm{R}_{\mathrm{a}}+\mathrm{R}_{\mathrm{ew}}\right) \cdot \mathrm{I}^{2}$

\section{Heat transfer Model}

The proposed stator heat transfer model is based on a steady state simple thermal resistance network established for a slot pitch. This network is globally presented in Fig. 5. One original contribution of the heat transfer study in our case consists in considering the heat transfer through the gap that can contribute significantly to the heat transfer of the generator, in the particular case of an immersed gap machine. The detailed expressions of the thirteen thermal resistances of Fig. 5 are not given in this paper for clarity reasons. However the thermal resistance values are directly derived from the classical heat transfer equations under steady-state conditions as in classical models which have been established for electrical machines as in [11]. Two modes of transfer are considered: conduction that occurs in the solid parts and convection that appears between the stator internal or external surfaces and the sea water. Thermal conductivity of iron, copper and coating material are established from material datasheets. The slot is estimated to be a homogenous material with an equivalent thermal conductivity that is established by the following expression.

$$
\lambda_{\text {eq }} \approx \lambda_{\text {ins }}(1-\gamma+\gamma /(1-\gamma))
$$

Where $\gamma=2 \mathrm{k}_{\mathrm{f}} /\left(1+\mathrm{k}_{\mathrm{f}}\right)$ and $\lambda_{\text {ins }}$ is the insulation material conductivity. The convective heat exchanges are modeled with a surface resistance

$$
\mathrm{R}_{\mathrm{cv}}=\left(\mathrm{hS}_{\mathrm{h}}\right)^{-1}
$$

where $S_{h}$ is the heat exchange surface and $h$ is the convective transfer coefficient. The convective coefficient at the stator external surface is evaluated by using classical test cases of fluid mechanics (flow along a plane surface). Concerning the gap, a model for a forced flow in an annular space is used: the Nusselt number is calculated thanks to the following correlated formula

$$
\mathrm{N}_{\mathrm{Nu}}=0.023 \mathrm{R}_{\mathrm{e}}^{0.8} \mathrm{P}_{\mathrm{r}}^{0.4}\left(\mathrm{D} / \mathrm{D}_{\mathrm{e}}\right)^{0.14}
$$

where $R_{e}$ is the Reynolds number and $P_{r}$ is the Prandtl number. The gap convective coefficient, $h_{\text {gap }}$, is then deduced

$\mathrm{h}_{\text {gap }}=\mathrm{N}_{\mathrm{Nu}} \lambda_{\mathrm{w}} / 2 \mathrm{~h}_{\mathrm{g}}$ 
where $\lambda_{\mathrm{w}}$ is the water thermal conductivity.

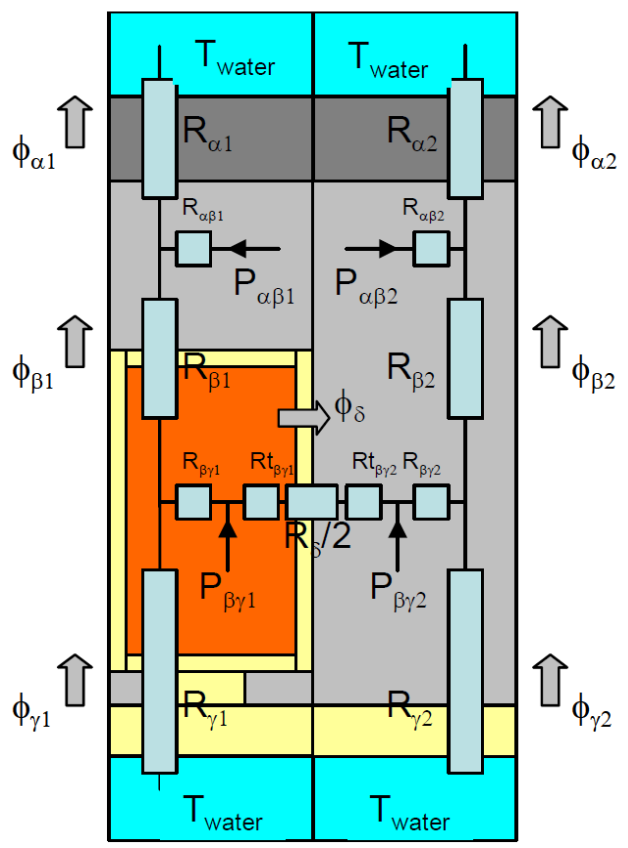

Fig.5 Considered thermal network

This thermal model allows to calculate the temperatures in the different parts of the generator. Thanks to this model, a constraint on the temperature level on the winding conductors can be taken into account in the global design process.

$\mathrm{T}_{\mathrm{Cu}}(\max ) \leq \mathrm{T}_{\max }$

Where $T_{c u}$ is the copper temperature and $T_{\max }$ is a limit temperature related to thermal class of the conductor.

\section{Hydrodynamic model of the mechanical gap}

This model which takes into account the viscosity effects related to the water flow in the mechanical gap of the generator, is based on the fully turbulent established flow between two plane plates. In this basic model, the influence of axial flow and curvature are neglected. In this analysis, one of the plates moves with a relative speed, $\mathrm{V}_{\mathrm{e}}$ $\left(\mathrm{V}_{\mathrm{e}}=\pi \mathrm{ND} / 60\right)$ where $\mathrm{N}$ is the rotating speed of the turbine in rpm. In this case the local Reynolds number can be calculated as follow.

$\operatorname{Re}_{\mathrm{e}}=\frac{\mathrm{V}_{\mathrm{e}} \cdot \mathrm{D}_{\mathrm{h}}}{\mathrm{v}_{\text {water }}}$

Where $v_{\text {water }}$ is the water viscosity and $D_{h}$ is a characteristic hydraulic diameter (In this particular case, this diameter is equal to the mechanical gap: $D_{h}=h_{g m}$ ). In this case the following expression from reference [12] links the friction coefficient, $\mathrm{C}_{\mathrm{d}}$ to the Reynolds number.

$1 / \sqrt{\mathrm{C}_{\mathrm{d}}}=2.04+1.768 \ln \left(\operatorname{Re}_{\mathrm{e}} \sqrt{\mathrm{C}_{\mathrm{d}}}\right)$

The determination of the $C_{d}$ coefficient allows us to calculate the expression of the viscosity losses in the gap.

$\mathrm{P}_{\mathrm{v}}=\mathrm{C}_{\mathrm{d}} \pi \mathrm{DL} \rho_{\mathrm{w}} \mathrm{V}_{\mathrm{e}}^{3} / 2=\mathrm{T}_{\mathrm{v}} \cdot 2 \pi \mathrm{N} / 60$

Where $\rho_{\mathrm{w}}$ is the water density and $T_{v}$ is the torque related to the viscous phenomena in the gap.

This model allows us to link the generator model to the hydrodynamic turbine model as presented in (4).
It can be noted that the heat production, related to these viscous phenomena in the gap, is not considered in the thermal model, as it is considered to be evacuated by the water axial open flow.

\section{E. Hydrodynamic model of the turbine}

In the Rankine Froude actuator disk model, the turbine rotor is considered as a zero thickness disk. It reduces the fluid upstream velocity by an induced factor (1-a) in the rotor disk. The downstream velocity is then reduced by a factor (1-2.a) as shown in fig.6. This theory males it possible to the power coefficient of the turbine as a function of the induced velocity factor $a$.

$$
\mathrm{C}_{\mathrm{p}}=4 \mathrm{a}(1-\mathrm{a})^{2}
$$

With

$$
\mathrm{C}_{\mathrm{p}}=\mathrm{P}_{\mathrm{m}} / \mathrm{P}_{\text {kin }} \text { and } \mathrm{P}_{\text {kin }}=\frac{1}{2} \rho_{\mathrm{w}} \mathrm{A}_{\mathrm{T}} \mathrm{V}^{3}
$$

Where $A_{T}$ is the is the cross-sectional area of the turbine, $V$ is the fluid velocity and $P_{k i n}$ is the kinetic power in the turbine. Equation (16) allows to establish the well known Betz limit which corresponds to the maximum value of $C_{p}$, $C_{p, \max }=16 / 27 \approx 0.59$ which is reached for $a=1 / 3$.

This very simple model can not be used to determine the performance of a turbine because the induced speed is unknown and depends both on the blade geometry and on the local flow in each part of the blades. This is why the model, used in this work, to determine the hydrodynamic performances of the turbine, from geometrical characteristics of the turbine blade and flow conditions, is an extension of the Rankine-Froude actuator disk model. This model is called "Blade Element Momentum" (BEM) method. It is used classically for the modeling of the blades of wind turbines. It has also been used for modeling the behavior of marine current turbines $[13,14]$ and has been validated in this case with experimental data [13]. In the BEM method the fluid velocity in each blade is supposed to be only dependent on the local radius of the blades $r$ as well as the blade speed and geometry. This is why the flow tube near the turbine disk is divided in a set of small annular coaxial tubes. Each of these tubes is characterized by a radial position $r$ and a radial thickness $\mathrm{dr}$ as shown in Fig. 7.

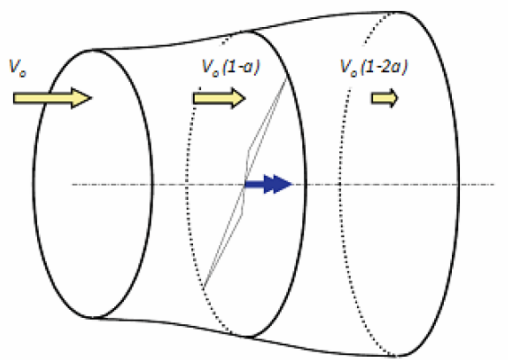

Fig. 6 Reduction of the fluid velocity (actuator disk theory)

For each blade element represented in Fig.8 (each element is characterized by a radial position, $r$, and a thickness, dr), the fluid velocity is modified by the blades. This modification is taken into account introducing the axial and tangential induced speed factors $a$ and $b$. 


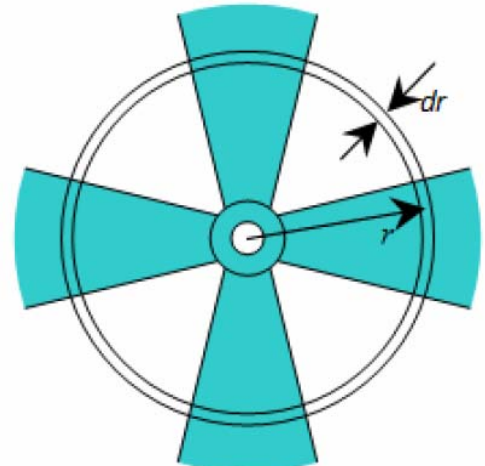

Fig. 7 : radial split of the turbine disk in disk element.

Thus the expression of the local relative velocity $\boldsymbol{V}_{\boldsymbol{R}}$ in the blade element frame (axial and tangential components) is

$\mathrm{V}_{\mathrm{R}}(\mathrm{r})=\mid \begin{gathered}(1-\mathrm{a}(\mathrm{r})) \cdot \mathrm{V}_{\mathrm{o}} \\ (1+\mathrm{b}(\mathrm{r})) \cdot 2 \pi \mathrm{r} \cdot \mathrm{N} / 60\end{gathered}$

To be able to determine these induced factors $a$ and $b$, for a given upstream incoming water speed $V_{o}$ and a given rotation speed $N$ (in $\mathrm{rpm}$ ) the local force exerted on the blade element can be calculated thanks to two method.

The first way is to express the force component as a function of local drag and lift coefficients, $C_{L}(r)$ and $C_{D}(r)$, as well as of the value of the relative velocity, $V_{R}$, and the attack angle, $\alpha$.

$$
\begin{aligned}
& d_{\mathrm{z}}(\mathrm{r})=-\mathrm{dL}(\mathrm{r}) \cdot \cos \phi(\mathrm{r})-\mathrm{dF}_{\mathrm{v}}(\mathrm{r}) \cdot \sin \phi(\mathrm{r}) \\
& \mathrm{dF}_{\mathrm{x}}(\mathrm{r})=d L(\mathrm{r}) \cdot \sin \phi(r)-\mathrm{dF}_{\mathrm{v}}(\mathrm{r}) \cdot \cos \phi(r)
\end{aligned}
$$

with $\phi(r)=\alpha(r)+\phi_{o}(r)$ and

$$
\begin{aligned}
& d L(r)=C_{L}(r) \cdot\left(\rho_{w} C(r) d r V_{R}^{2}(r) / 2\right) \\
& d_{v}(r)=C_{D}(r) \cdot\left(\rho_{w} C(r) d r V_{R}^{2}(r) / 2\right)
\end{aligned}
$$

$C(r)$ is the chord value at radius $\mathrm{r}$.

Like the incoming upstream velocity, $V_{o}$ and the rotational speed $N$, these local drag and lift coefficients are inputs of the algorithm. Classically these coefficients have to be determined 'a priori', for each studied 2D foil shape (NACA foils for example), from experimental tests as functions of the local Reynolds Number $\left(\operatorname{Re}(\mathrm{r})=\mathrm{C}(\mathrm{r}) \mathrm{V}_{\mathrm{R}}(\mathrm{r}) / \mathrm{v}_{\mathrm{w}}\right)$ and the attack angle $\alpha$. That means that the expressions of $d F_{z}$ and $d F_{x}$ in (18) and (19) can be considered as implicit functions of the induced factors $a$ and $b$ (it is obvious that $V_{R}, \alpha$ and $\phi$ are functions of $a$ and $b)$.

A second method can be used to express the local force. This force can be calculated from the rate of change of momentum in the blade element. Two additional expressions are thus established.

$$
\begin{aligned}
& \mathrm{dF}_{\mathrm{z}}(\mathrm{r})=\frac{-\left(2 \mathrm{a}(\mathrm{r}) \mathrm{V}_{\mathrm{o}}\right) \cdot \rho_{\mathrm{w}}(2 \pi \mathrm{rdr}) \cdot \mathrm{V}_{\mathrm{o}}(1-\mathrm{a}(\mathrm{r}))}{\mathrm{Z}} \\
& \mathrm{dF}_{\mathrm{x}}(\mathrm{r})=\frac{(2 \mathrm{~b}(\mathrm{r}) 2 \pi \mathrm{rN} / 60) \cdot \rho_{\mathrm{w}}(2 \pi \mathrm{rdr}) \cdot \mathrm{V}_{\mathrm{o}}(1-\mathrm{a}(\mathrm{r}))}{\mathrm{Z}}
\end{aligned}
$$

Where $Z$ is the number of blades of the turbine.

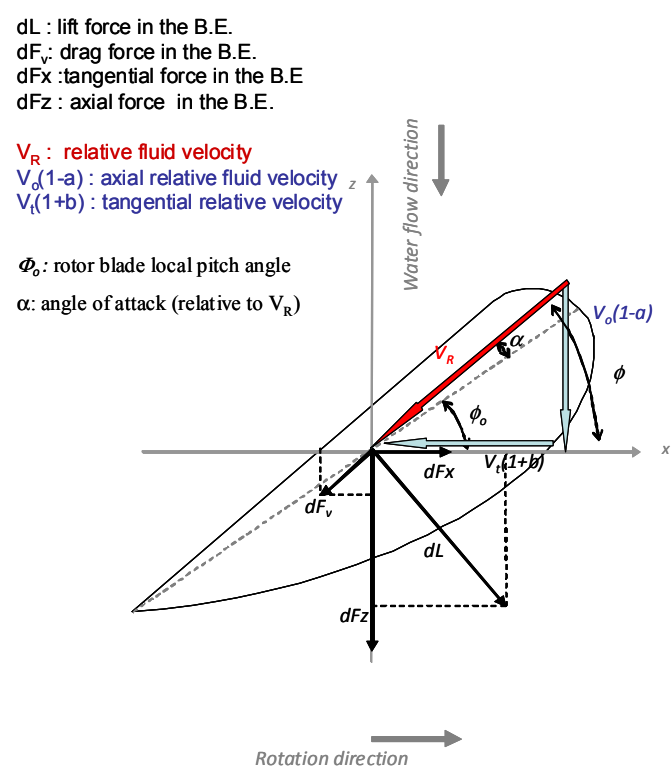

Fig. 8 : Forces and water relative water speed in a blade element

Equations (18), (19), (20) and (21) lead to a set of 2 equations which are implicit and non-linear functions of the induced factor $a$ and $b$.

$$
\begin{aligned}
& \sigma(r) \cdot\left(C_{L}(r) \cdot \cos \phi(r)+C_{D}(r) \cdot \sin \phi(r)\right) \cdot V_{R}^{2}(r) /\left(4 V_{o}^{2}\right) \\
& =a(r)(1-a(r)) \\
& \sigma(r) \cdot\left(C_{L}(r) \cdot \sin \phi(r)-C_{D}(r) \cdot \cos \phi(r)\right) . \\
& V_{R}^{2}(r) /\left((8 \pi n r) V_{o}\right)=b(r)(1-a(r))
\end{aligned}
$$

Where $\sigma(\mathrm{r})=\mathrm{ZC}(\mathrm{r}) /(2 \pi \mathrm{r})$

Some additional correction factors are used in this algorithm. The Grauert empirical expression is used in place of (22) if a turbulent wake condition appears (the condition of turbulent wake apparition is tested at each iteration).

$$
\begin{aligned}
& \mathrm{a}(\mathrm{r})=0.143+\sqrt{0.6427 . \mathrm{C}_{\mathrm{dax}}(\mathrm{r})-0.55106} \\
& \text { If } \mathrm{C}_{\mathrm{dax}}(\mathrm{r})=\mathrm{ZdF}_{\mathrm{z}}(\mathrm{r}) /\left(\rho_{\mathrm{W}} \cdot \mathrm{V}_{\mathrm{o}}^{2} \pi \mathrm{rdr}\right) \geq 0.96
\end{aligned}
$$

The Prandt correction factor is also introduced in the right part of (22) and (23) in order to take into account blade root effects ( $a$ is replaced by $F_{l}(r) . a$ and $b$ by $\left.F_{l}(r) . b\right)$.

with $\mathrm{F}_{\mathrm{L}}(\mathrm{r})=\frac{2}{\pi} \arccos \left[\left(\exp \left(\mathrm{Z}\left(1-\mathrm{r} / \mathrm{r}_{\mathrm{h}}\right) /(2 \sin \phi(\mathrm{r}))\right)\right]\right.$

Where $r_{h}$ is the internal radius of the blades.

It can be noted that the blade tip effects can be neglected in a ducted turbine.

For each of the blade element it is then possible to calculate the $a$ and $b$ factors by an iterative resolution process of the obtained set of equations. In our case this resolution is based on Newton-Raphson method.

Then the global thrust, $T$, and the global mechanical torque, $Q$, of the turbine can be determined by summation of the $N_{s p}$ small sectors contributions of thickness $d r$.

$$
\mathrm{Q}=\mathrm{Z} \sum_{\mathrm{k}=1}^{\mathrm{N}_{\mathrm{sp}}}\left(\mathrm{r}_{\mathrm{h}}+(\mathrm{k}-1 / 2) \cdot \mathrm{dr}\right) \times \mathrm{dF}_{\mathrm{x}}\left(\mathrm{r}_{\mathrm{h}}+(\mathrm{k}-1 / 2) \cdot \mathrm{dr}\right)
$$




$$
\mathrm{T}=\mathrm{Z} \sum_{\mathrm{k}=1}^{\mathrm{N}_{\mathrm{sp}}} \mathrm{dF}_{\mathrm{z}}\left(\mathrm{r}_{\mathrm{h}}+(\mathrm{k}-1 / 2) \cdot \mathrm{dr}\right)
$$

This method allows to determine the hydrodynamic performance (torque, power, thrust) of a given turbine geometry (number of blade, foil shape, chord law, shrill law) for each value of the upstream incoming water speed and rotation speed.

\section{DESIGN RESULTS}

The presented methodology is applied to the specifications of a small marine turbine generator for a race sail boat. The design is done by considering the average velocity of the "Orange II" maxi-catamaran during the "Jules Verne's trophy" in 2005. This operating point corresponds to a water velocity of $9.20 \mathrm{~m} / \mathrm{s}$ (around 20 knots) in the turbine disk. We have also chosen a turbine diameter of $20 \mathrm{~cm}$. These diameter and velocity can generate a theoretical total kinetic power in the turbine disk around $12.5 \mathrm{~kW}$. It can be noted that the corresponding additional drag is not significant in comparison of the global sail propulsion force. We have fixed the number of blades of the turbines ( 5 blades) and the chord of the blades which is equal to the $1 / 8$ of the turbine radius. The shape of the blades corresponds to a NACA0018 hydrofoil. The optimization of the blades is done determining an optimal twist law. This twist law $\left(\phi_{o}(\mathrm{r})\right)$ is characterized by 5 design variables: $k_{o}$, $k_{1}, k_{2}, \lambda_{o}$ and $\alpha_{o}$ and defined as follow

$\phi_{0}(\mathrm{r} / \mathrm{R})=\tan ^{-1}\left(\frac{\mathrm{f}(\mathrm{r} / \mathrm{R})}{\lambda_{\mathrm{o}} \mathrm{r} / \mathrm{R}}\right)-\alpha_{\mathrm{o}}$

with $\mathrm{f}(\mathrm{r} / \mathrm{R})=\mathrm{k}_{\mathrm{o}}+\mathrm{k}_{1} \cdot \mathrm{r} / \mathrm{R}+\mathrm{k}_{2} \cdot(\mathrm{r} / \mathrm{R})^{2}$

The design variables of the electrical machine are its main geometrical variables defined in fig.4. Some constraints are fixed for these geometrical parameters. The number of slots by phase and by pole is fixed to 0.5 which corresponds to concentrated windings. Some constraints are fixed to limit the geometrical dimensions. These constraints are linked to maximal induction level in iron, maximal electric frequency or mechanical constraints. As an example the electrical frequency is limited to $140 \mathrm{~Hz}$ to be able to use classical soft magnetic laminations. The radial thickness of the machine is limited to $20 \%$ of the diameter of the turbine for hydrodynamics reasons (the duct radial dimensions are constrained in order to limit the global drag forces on the turbine structure).

Two approaches are then considered. In the first one the blades and the generator are designed separately and in a sequential way. This first approach is the classical design approach for this kind of systems. The second approach is based on a global design process where the turbine and the generator are designed at the same time as shown in fig.3

\section{A. Separate design approach results}

In the first approach, the blades of the turbine are determined firstly, to optimize the power coefficient of the turbine. Then a design process is used to optimize the electrical machine in terms of efficiency. As shown in fig.9 (red line). The obtained optimal turbine design leads to an optimal operating speed of the turbine around $3900 \mathrm{rpm}$ and an optimal power coefficient of the turbines blades around 0.5 . (The corresponding tip speed ratio $\lambda=2 \pi R N /\left(60 . V_{o}\right)$ around 4.3.) Unfortunately in this case, it becomes impossible to respect simultaneously both constraints related to the electrical frequency and the radial thickness. Indeed, the limitations on the electrical frequency, lead to the choice a small number of pole pairs. It leads to high values of the thicknesses of rotor and stator cores. So the electrical machine can not be integrated in the duct surrounding the blades. Thus no machine respecting all the design constraint can be found. This example shows that the classical design approach, where blade and generator designs are separated, is not really efficient to design such a rim driven system.

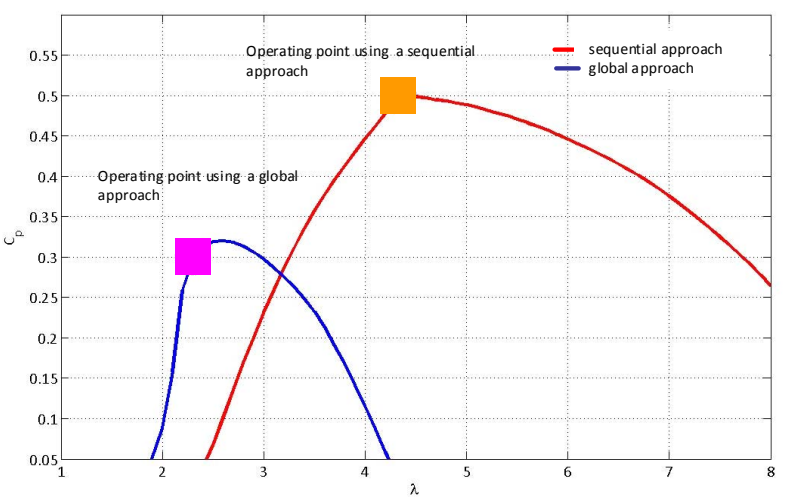

Fig.9 : Power coefficient, $\mathrm{C}_{\mathrm{p}}$, versus tip speed ratio

$\left(\lambda=\mathrm{TSR}=2 \pi \mathrm{RN} /\left(60 . \mathrm{V}_{\mathrm{o}}\right)\right)$ of the two designed turbines (hydrodynamic characteristic only)

\section{B. Global design approach}

A global design approach using the scheme of Fig. 3 is used in a second step. In this case all the constraints and the model presented in section III are used in a unique optimization approach, in order to maximize the global efficiency of the turbine. An optimal turbine and machine design has been found and is presented in fig. 10 and 11 and table I. In this case the efficiency of the electrical generator is $83 \%$ (taking into account the gap viscosity losses).

The electrical power extracted by the system, at the rated operating point, is $3.12 \mathrm{~kW}$. The Joule losses, Iron losses and viscosity losses in the gap are respectively $196 \mathrm{~W}, 45 \mathrm{~W}$ and $375 \mathrm{~W}$. We can notice that the viscosity effects limit the efficiency of the system. These results show that a global coupled approach is necessary for the design of this kind of system.

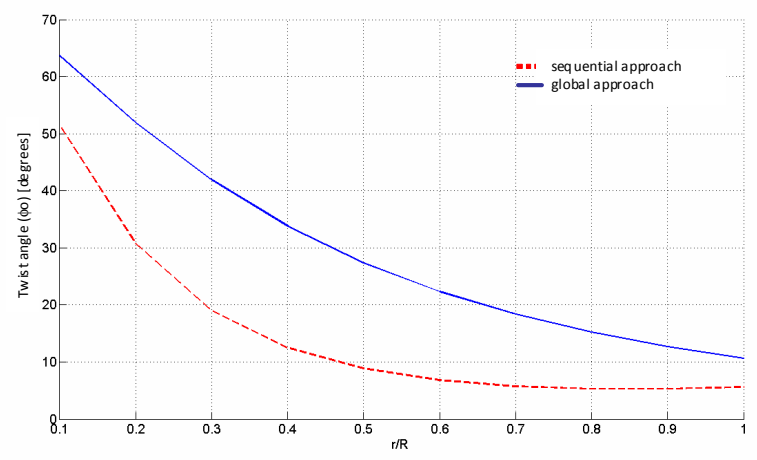

Fig. 10 : Twist law of the two blade designs as a function of the reduced $\operatorname{radius}(\mathrm{r} / \mathrm{R})$ 


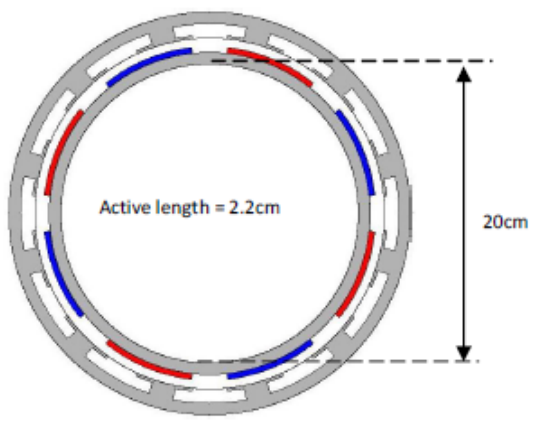

Fig.11 electrical generator design obtained by a global coupled approach.

TABLE I

MAIN DimENSIONS OF THE ElECTRICAL GENERATOR

\begin{tabular}{|l|l|}
\hline Active length & $\mathrm{L}=2.2 \mathrm{~cm}$ \\
\hline Number of pole pairs & $\mathrm{p}=4$ \\
\hline Magnet height & $\mathrm{h}_{\mathrm{m}}=4 \mathrm{~mm}$ \\
\hline Slot height & $\mathrm{h}_{\mathrm{s}}=8 \mathrm{~mm}$ \\
\hline $\begin{array}{l}\text { Total mechanical gap } \\
\text { (including sealing } \\
\text { material) }\end{array}$ & $\mathrm{h}_{\mathrm{g}}=4 \mathrm{~mm}$ \\
\hline Proportion of teeth & $\mathrm{k}_{\mathrm{T}}=0.25$ \\
\hline $\begin{array}{l}\text { Magnet to pole width } \\
\text { ratio }\end{array}$ & $\beta=0.72$ \\
\hline Stator rms electric load & $\mathrm{A}_{\mathrm{L}}=34.1 \mathrm{kA} / \mathrm{m}$ \\
\hline $\begin{array}{l}\text { Current density in } \\
\text { copper }\end{array}$ & $\mathrm{J}=9.5 \mathrm{~A} / \mathrm{mm}^{2}$ \\
\hline
\end{tabular}

\section{CONCLUSION}

In this paper a global approach for the design of a rimdriven marine current generator to provide onboard energy a sail race ship is proposed. In this particular system, the generator is located in a duct surrounding the turbine blades and the gap of the generator is immersed. The approach proposed in this paper, associates, in a global efficiency optimization process, several models of the physical phenomena in the system. EM and thermal models of the generator and hydrodynamics models of the turbine blades and of the flow in the immersed gap are associated. For the studied example, it is shown that the classical approach where the turbine blade and the electrical machine are designed separately is not relevant. A global approach is thus proposed in order to obtain relevant design results.

\section{REFERENCES}

[1] M. Barcaro, N. Bianchi, S. Bolognani, Hybrid Electric Propulsion System Using Submersed SPM Machine, in proccedings of ICEM'2008, Villamoura Portugal, 6pp.

[2] M. Lea et al., "Scale model testing of a commercial rim-driven propulsor pod" in J. of Ship Prod., May 2003, Vol. 19, ํ2, pp.121130.

[3] Ø. Krøvel, R. Nilssen, S.E. Skaar, E. Løvli, N. Sandoy, "Design of an integrated 100kW Permanent Magnet Synchronous Machine in a Prototype Thruster for Ship Propulsion" in Proceedings of ICEM'2004, Cracow, Poland, Sept. 2004, pp.117-118.

[4] S.M. Abu Shark, S.H. Lai and S.R. Turnock, Structurally integrated brushless $\mathrm{pm}$ motor for miniature propeller, IEE Proc. Electrical Power Applications, Vol. 151, N`5, pp. 513-519, 2004

[5] H.L. Williams, Hydroelectric Turbine for producing electricity from a water current, Patent US 6648589 B2, 2003.

[6] H.L. Williams, Hydroelectric Turbine, Patent US 6957947 B2, 2005.

[7] L. Drouen, J.F. Charpentier, F. Hauville, E. Semail, S. Clenet, ,"A Coupled Electromagnetic/Hydrodynamic Model for the Design of an Integrated Rim-Driven Naval Propusion System", in Proceedings ELECTRIMACS 2008, Québec, Canada, 8-11 juin 2008
[8] L. Drouen, J.F. Charpentier, E. Semail, S. Clenet, Study of an Innovative Electrical Machine fitted to Marine Current Turbines", in proc. IEEE-OCEAN 2007, Aberdeen, Scotland, UK, June 18-21, 2007.

[9] Z.Q. Zhu, D. Howe, E. Bolte, B. Ackermann, Instantaneous magnetic field distribution in brushless permanent magnet dc motors, Part I : Open-circuit field, IEEE transactions on magnetics, Vol.29, $\mathrm{N}^{\circ} 1$, pp. 124-135, Jan. 1993

[10] Matagne E., Slot effect on the air-gap reluctance Carter-like calculation suitable for electric machines with large air-gap or surface-mounted permanent magnets, ELECTROMOTION 15 (2008) 171-176

[11] A. Grauers, Design of direct-driven permanent-magnet generators for wind turbines, Ph.D. dissertation, Chalmers University of Technology, Göteburg, Sweden, 1996.

[12] J.E. Vrancik, Prediction of windage power loss in alternators, Nasa technical note NASA TN D-4849, Lewis Research Center, Cleveland, Ohio, USA, October 1968.

[13] A.S. Bahaj et al., "Power and thrust measurements of marine current turbines under various hydrodynamic flow conditions in a cavitation tunnel and a towing tank," Renewable Energy, vol. 32, pp. 407-426, 2007.

[14] S.E. Ben Elghali, R. Balme, K. Le Saux, M.E.H. Benbouzid,J.F. Charpentier, and F. Hauville, - A Simulation Model for the Evaluation of the Electrical Power Potential Harnessed by a Marine Current Turbine in the Raz de Sein - IEEE Journal on Oceanographic engineering, Vol32 $\mathrm{n}^{\circ} 4$ Oct 2007, pp786-797

\section{BIOGRAPHIES}

Laurent Drouen was born in Mantes-la-Jolie, France, in 1973. He received the M.Sc. degree in electrical engineering from Supélec, Gif sur Yvette, France in 1997. From 1997 to 2005, he worked as an electrical engineer on various projects related to HV Networks and Power Electronics. He obtained a Ph.D degree at the Research Institute of the French Naval Academy in the field of electrical machines applied to naval propulsion and tidal energy extraction in 2010 . He is now working as a Power electrical Engineer in Alstom Company,Tarbes,France.

Jean Frédéric Charpentier (M'02) received the M.Sc. and PhD degree in electrical engineering in 1993 and 1996 respectively and the Habilitation à Diriger les Recherches degree in 2010. From 1996 to 1997 he was a post doctoral fellow at Laval University, Québec, Canada and an assistant Professor at the University Institute of Technology of Brest, France from 1997 to 2002,. Since 2002, he has been an Associate Professor in the French Naval Academy, Brest, France. His current research interests include modeling and design on electrical machines and drives for variable speed electrical naval propulsion systems and marine renewable energy.

Eric Semail is graduated in 1986 from the Ecole Normale Superieure, in France. He received Ph.D. degree in 2000 on « Tools and studying method of polyphase electrical systems, Generalization of the space vector theory ». He became associate professor at Engineering school of ARTS et METIERS PARISTECH in 2001 and full professor in 2010. In Laboratory of Electrical Engineering of Lille (L2EP) in France, his fields of interest include design, modeling and control of multi-phase drives (converters and AC Drives). More generally he studies Multi-machine and Multi-converter systems.

Application fields: automotive, marine and offshore wind power.

Stéphane Clenet received an engineering degree in 1990 and a Ph.D degree in 1994 both from the Institut National Polytechnique de Toulouse. From 1994 till 2002 he was Assistant Professor with the Electrical Engineering department of the University of Lille. Since September 2002 he is professor at the Ecole Nationale Supérieure d'Arts et Métiers. He teaches courses on electrical machines and power electronics. His research concerns the numerical modelling of electromagnetic devices working at low frequency. 